\begin{tabular}{|c|c|}
\hline \multirow{3}{*}{ 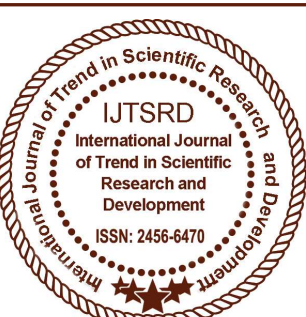 } & $\begin{array}{l}\text { International Journal of Trend in Scientific } \\
\text { Research and Development (IJTSRD) }\end{array}$ \\
\hline & International Open Access Journal \\
\hline & ISSN No: 2456 - 6470 | www.ijtsrd.com | Volume - 2 | Issue - 5 \\
\hline
\end{tabular}

\title{
A Integrated Medical Project Design in Godavadi Village
}

\author{
Umeshkumar B. Hadiya ${ }^{1}$, Farrukh Javed ${ }^{1}$, Kuldeepsinh Y. Jadeja ${ }^{2}$ \\ ${ }^{1}$ UG student, ${ }^{2}$ Lecturer \\ Department of Civil Engineering, BMCET, Surat, Gujarat, India
}

\begin{abstract}
The aims of writing this topic are the current practices related to the Primary Healthcare Centre taken in the form of human well being. The other purpose is to provide some suggestions and recommendation to improve the Primary Healthcare Centre in village. Primary healthcare is the day-to-day care needed to protect, maintain, or restore our health. The paper attempts to understand the important role played by the formal sector engaged in Primary Healthcare Centre in our village.
\end{abstract}

Keywords: Health system, Human resources, Primary health care, Public health, WHO, morbidity prevalence, maternal and child death etc.

\section{INTRODUCTION}

Health of the people is the real foundation upon which all their happiness depend. Health is one of the vital indicators of quality of human life because good health always positively contributes to economic development. Therefore, health is regarded as a vital component in the growth and development of any country. The World Health Organization (WHO) is a specialized agency of the United Nations that is concerned with international public health. It was established on 7 April 1948, and is headquartered in Geneva, Switzerland. Its predecessor, the Health Organization, was an agency of the League of Nations. Health is a state of complete physical, mental and social well being and not merely absence of disease or infirmity (WHO Definition of Health 1948).

Health is a fundamental human right. The state holds the responsibility for the health of its people. National Governments all over the world are striving to expand and improve their health care services. The current

situation is urban oriented, mostly curative in nature and accessible to a small part of population. The period covered by the study reported on here corresponds with that of the Report, allowing for a comparison of achievements and challenges in one primary health care centre vis-a-vis the WHO standards.

This paper provides from good practice in PHC presented as a step by step guide. The Godavadi village population is large. In Godavadi Village there is only One Sub-Health Care Centre which is very small. The purpose of this Paper is not merely adding to the existing knowledge on $\mathrm{PHC}$, but to provide practicable ideas for implementation for better health.

\subsection{NEED OF STUDY}

The Health Centre is the basic structural and functional unit of the public health services in village. In Godavadi Village there is only One Sub-Health Care Centre which is very small and although not regulated regularly because of all services or facility regarding with Health Care is not available. So we decided to proposed some Health Care Infrastructure which facilitate some necessary services concerned with health. The main role of primary health care is to provide continuous and comprehensive care to the patients. It also helps in making the patient available with the various social welfare and public health services initiated by the concerned governing bodies and other organizations. The other major role of a health care centre is to offer quality health and social services to the underprivileged sections of the society. In Godavadi village do not have the any place for growth of human Physical and Psychic So we have design the Yoga centre and Gymnasium. 


\section{FIELD STUDY}

Godavadi village in Mandvi taluka in Surat district of Gujarat state, India. Located in rural part of Surat district of Gujarat, it is one among the 103 villages of Mandvi block of Surat district. It is located $53 \mathrm{~km}$ towards North from District headquarters Surat. 291 $\mathrm{km}$ from State capital Gandhinagar. The geographical area of village is 74102 hectare. The Godavadi village having state code 42 and the village code is 524052 . The BHUVAN satellite map of village is shown in figure below:

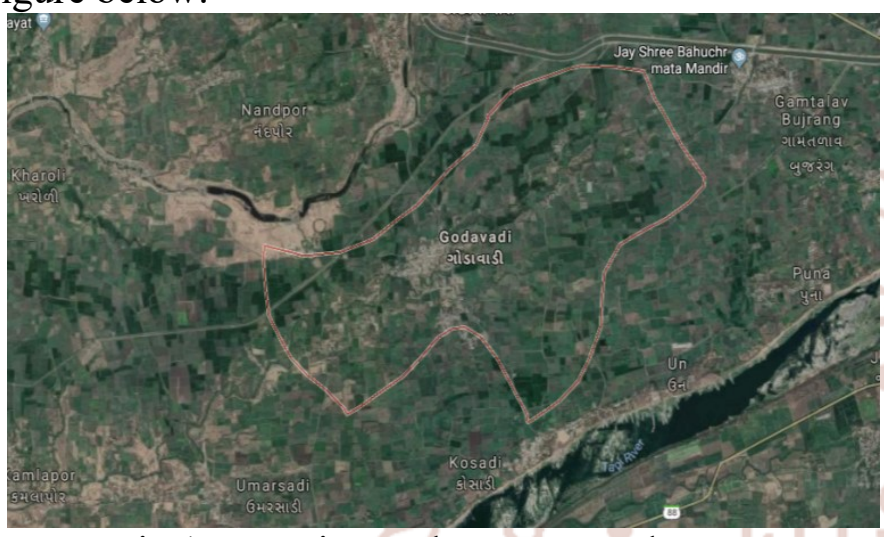

Fig 1: Location and Layout Study Area

The geographical coordinates are 21.253860 latitude, 73.229217 longitude. The pin code of village is 394163 and the village code is 524052 . The surat is the district of this village with district code 492 .

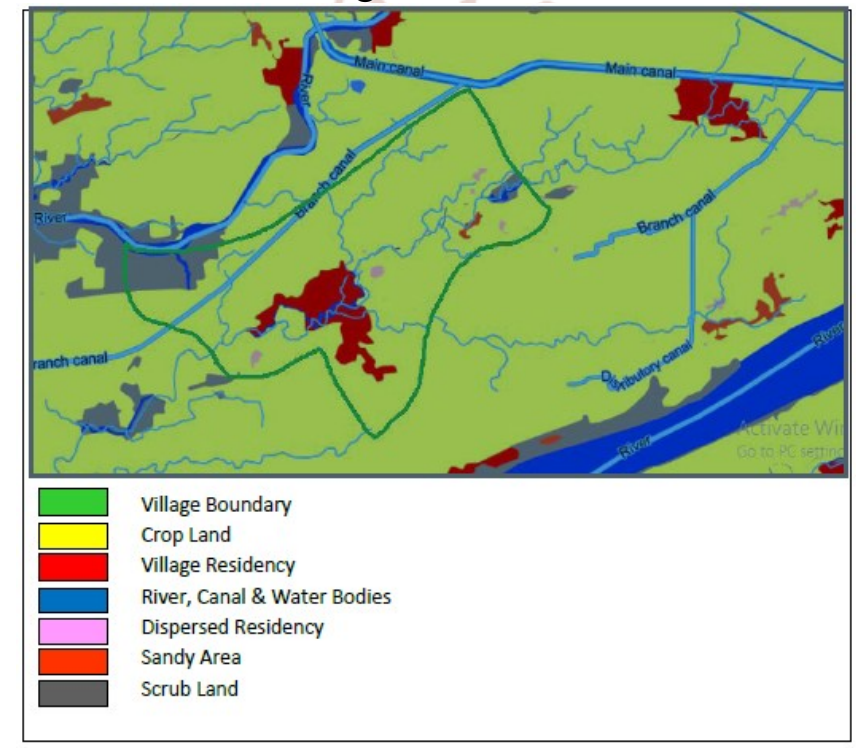

Fig 2: Land use map of Godavadi village

The total population of Godavadi is 3915 out of which 1979 are males and 1963 are females, thus the average sex ratio of Godavadi is 978. According to Census 2001 total population of Godavadi village was nearly $1.6 \%$ of total rural population of Mandvi district. The population of children of age 0-6 years in Godavadi village is 373 which is approximately $10 \%$ of the total population. There are 199 male children and 174 female children.thus as per the Census 2011 the child sex ratio of Godavadi is 874 which is less than average sex ratio (978).

\begin{tabular}{|l|l|l|l|l|l|}
\hline $\begin{array}{c}\text { Sr. } \\
\text { No. }\end{array}$ & Census & $\begin{array}{c}\text { Popula- } \\
\text { tion }\end{array}$ & Male & Female & $\begin{array}{c}\text { Total } \\
\text { House- } \\
\text { hold }\end{array}$ \\
\hline 1. & 2001 & 2261 & 1143 & 1118 & 539 \\
\hline 2. & 2011 & 3915 & 1979 & 1936 & 804 \\
\hline
\end{tabular}

Table 1: Physical growth of people of Godavadi village

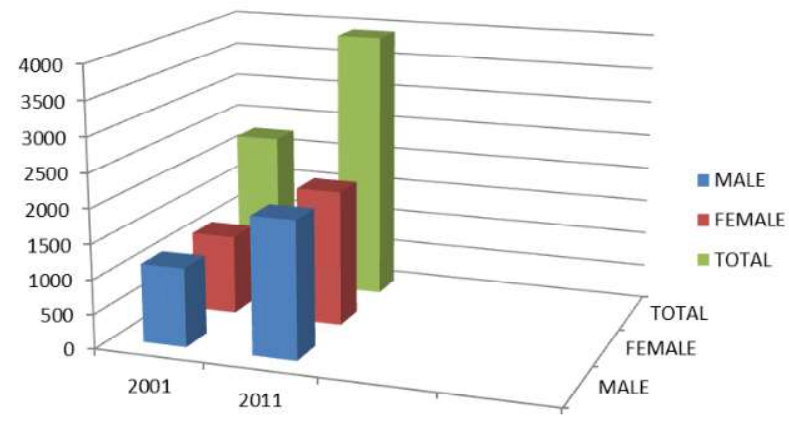

Fig 3: Demographical growth of village

\section{SCOPE OF STUDY}

Developing a report card about Health care facilities available at Primary Health Center in Godavadi village.

To assess the current scenario of Child care services and Maternal Care Services and General Health Care Services including , Indoor, Emergency services, in terms of quality and Capacity in Primary Health Centers in Godavadi.

To identify the shortfalls at PHC level in Godavadi village.

$>$ Critical review and evaluation of National Health Programme at PHC of Godavadi village.

Service Quality assessment of PHC.

To suggest measures to improve the performance of primary health care system in the area.

To assess the impact of National Rural Health Mission on Child care, Maternal Care and general.

Included in PHC is Blood bank so village people easily get the blood. 
International Journal of Trend in Scientific Research and Development (IJTSRD) ISSN: 2456-6470

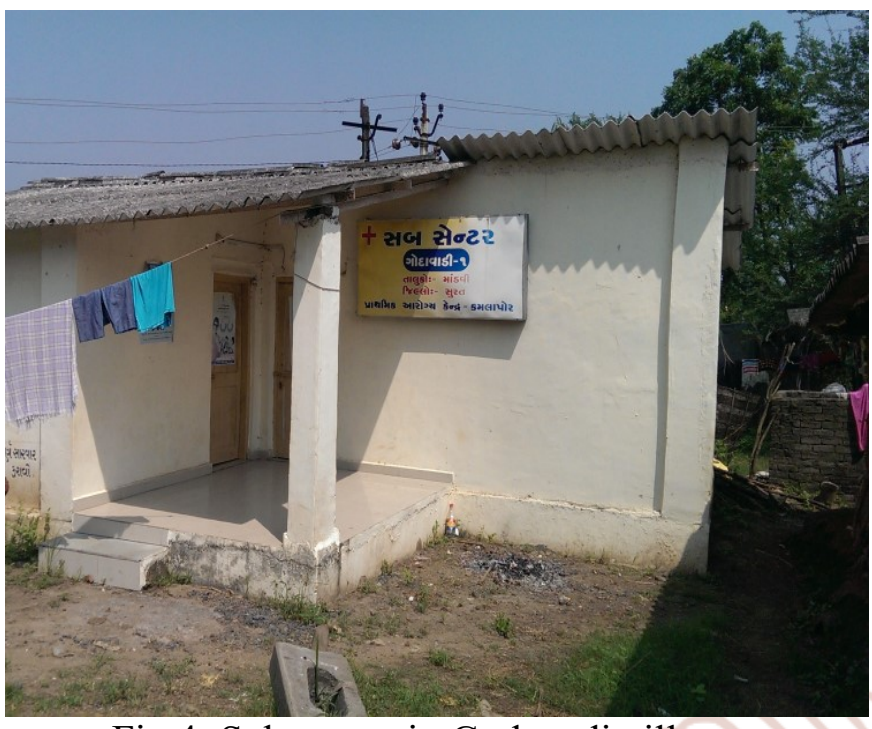

Fig 4: Sub centre in Godavadi village
4. SWOT ANALYSIS

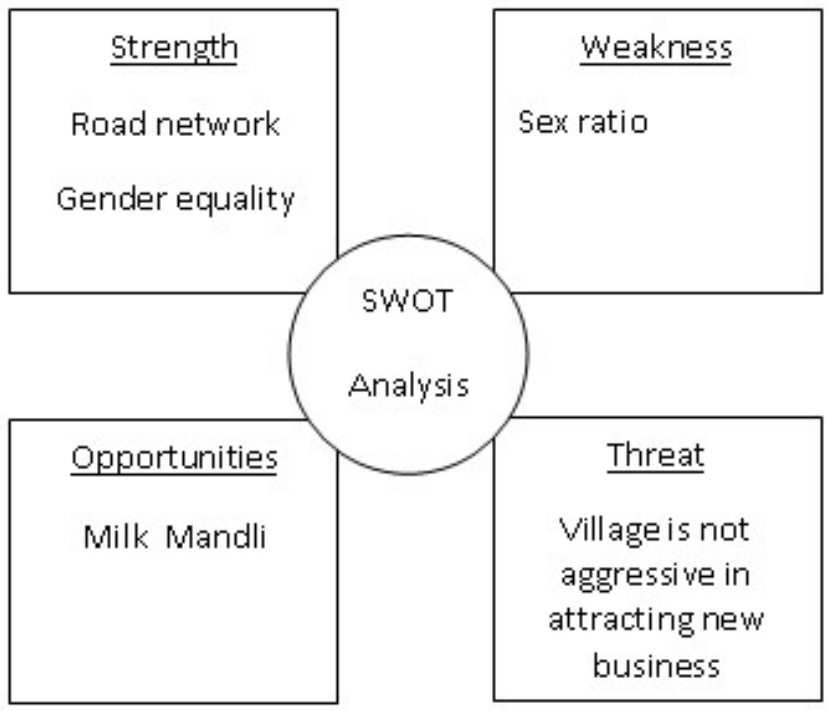

Fig 5: SWOT Analysis

\section{PRIMARY HEALTH CARE CENTRE (PHC)}

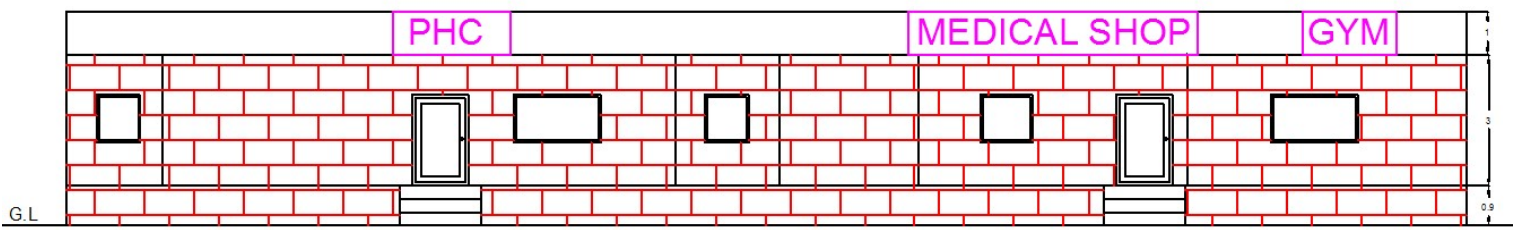

\section{ELEVATION}
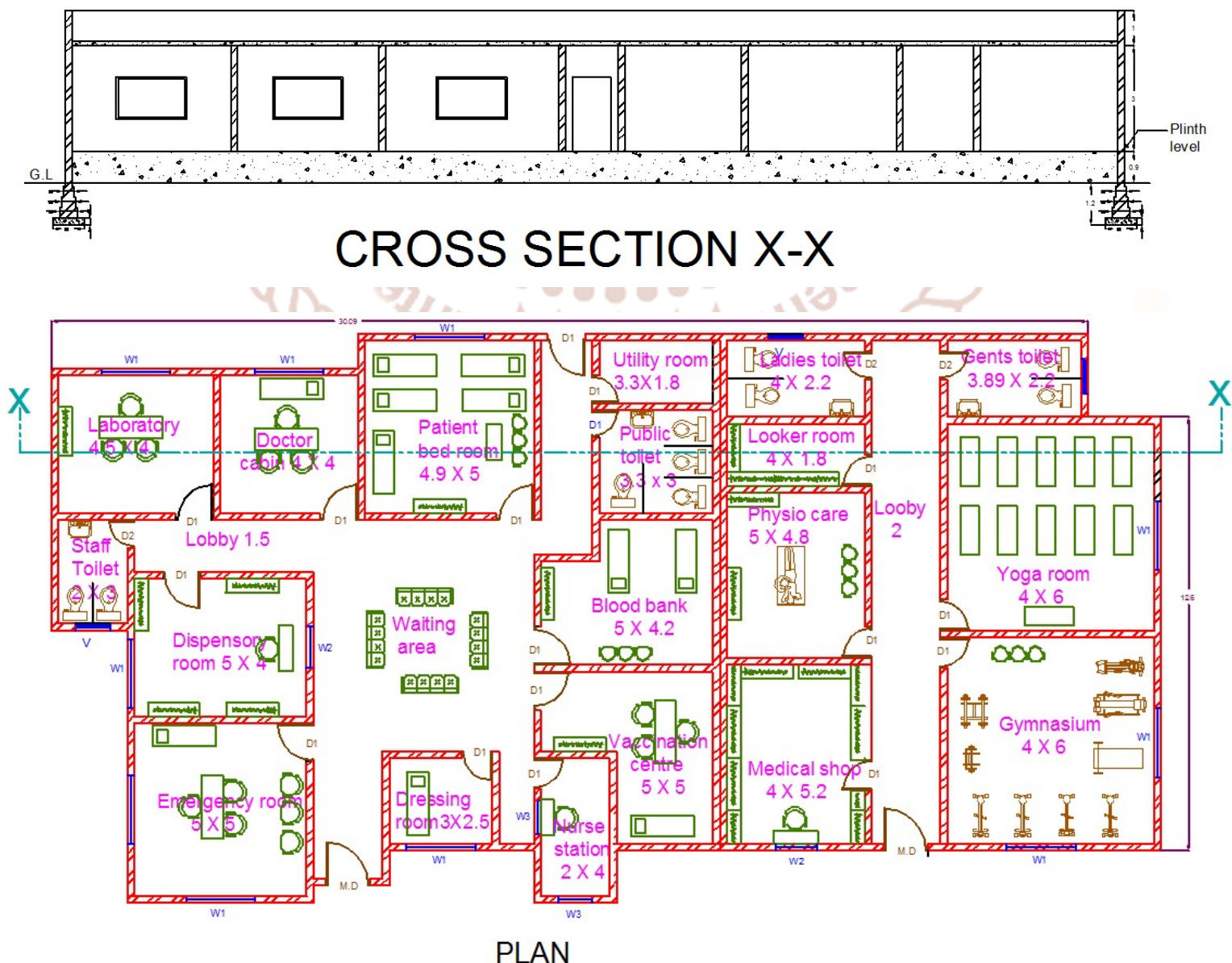

Fig 6: Plan, Elevation \& Section of PHC 


\section{CONCEPT OF PHC}

This is essential health care that meets health needs of the majority of the people. The care should be accessible to individuals and families and communities served and communities should participate in planning and implementation of PHC. We have design the yoga centre Physiocare Gymnasium so people growth of Physical and Psychic

\section{BENEFITS}

The Health Centre is the basic structural and functional unit of the public health services in village. The main role of primary health care is to provide continuous and comprehensive care to the patients. It also helps in making the patient available with the various social welfare and public health services initiated by the concerned governing bodies and other organizations. The other major role of a health care centre is to offer quality health and social services to the underprivileged sections of the society.

$>$ It offers the quality health and social services to the underprivileged sections of the society.

$>$ It is main Facility of the develop in village.

$>$ People easily safe of the health.

$>$ PHC generally use is the all village people.

$>$ The implement of the economic and Eco-friendly.

$>$ This facility is a primary level and It is Smart Village concept.

$>$ It is very important and Use full facility.

\section{CONCLUSION}

The health is the most important in our life. In PHC design we have include the Blood Bank, Vaccination etc. So easily available Blood in near village. Reduce the maternal and child death. Village people are aware the yoga and people do the yoga regular it is growth for the Physical human.

\section{REFERENCES}

1. Dutta Indeanee (2007) Health and Health Care in Assam, a status report. Published by Centre for Enquiry into Health and Allied Themes (CEHAT).

2. George A. V. (1999). "Health care system in Kerala: A care of primary health centres in Kazhikode district". Department of Economics, Dr. John Matthai centre, University of Calicut.

3. WHO (1978). Alma-Ata 1978. Primary Health Care. Health for All. Sr. No. 1. World Health Organization. Geneva.

4. World Health Organization (2000). The World Report 2000: Health Systems Improving Performance.

5. Gupta, Monica Das (2005). "Public health in India: Dangerous Neglect". Economic and Political weekly, XL(49) 